\title{
A Review into Effective Classroom Management and Strategies for Student Engagement: Teacher and Student Roles in Today's Classrooms
}

\author{
Hayley Franklin ${ }^{1}$, Ingrid Harrington ${ }^{1}$ \\ ${ }^{1}$ School of Education, University of New England, NSW, Australia \\ Correspondence: Dr. Ingrid Harrington, School of Education, University of New England, NSW, Australia.
}

Received: August 27, 2019

Accepted: September 16, 2019

Online Published: September 16, 2019

doi:10.11114/jets.v7i12.4491

URL: https://doi.org/10.11114/jets.v7i12.4491

\begin{abstract}
A teacher's role encompasses far more than just imparting curricula outcomes to their students: they need to equip students with the necessary tools to experience social and academic success both inside the classroom and beyond it. Teachers need to empower students with the means to critically analyse the world around them in order to develop into critical independent thinkers. Students need to be proficient in utilising skills associated with higher levels of thinking, that will empower them with the ability to identify, analyse and evaluate the infinite volume of information available through our rapidly changing digital world. Just as teachers need to take responsibility for the various methods of teaching and instruction in the classroom, it is essential for students to take ownership of the learning process, to ensure future success in university environments, where sustained personal effort and metacognitive skills are fundamental to academic success. The object of the review of the literature surrounding the roles of teacher and student, effective classroom management strategies, and successful evidence-based teaching and learning pedagogies, is to assist new and experienced teachers in the promotion of a positive classroom experience for all.
\end{abstract}

Keywords: classroom management, student engagement, teacher role, student role

\section{Introduction}

The role of the teacher is undoubtedly to instruct and the student to learn, however this simplistic view of classroom practice fails to differentiate the difference between what constitutes successful classroom learning for one set of students and simply surviving another year of education for others. If the number one predictor of future success and happiness for our students going into adult life is the number of years engaged in learning (Hattie, 2013), then successful classrooms are more than test scores. Successful classrooms foster enthusiasm and motivation for learning, active participation and high levels of engagement, with teachers not only knowing the content to be taught, but also knowing the impact their teaching has on their student's ability to become self-directed lifelong learners (OECD, 2005). Successful classrooms are the result of a set of shared roles and responsibilities belonging to teachers and students. Underpinned by theoretical perspectives, beliefs and assumptions of these roles and responsibilities fall into four main domains of classroom practice. These domains include: classroom teaching and learning, classroom behaviour management and the classroom environment - social aspects and physical space as illustrated below in Figure 1 . 


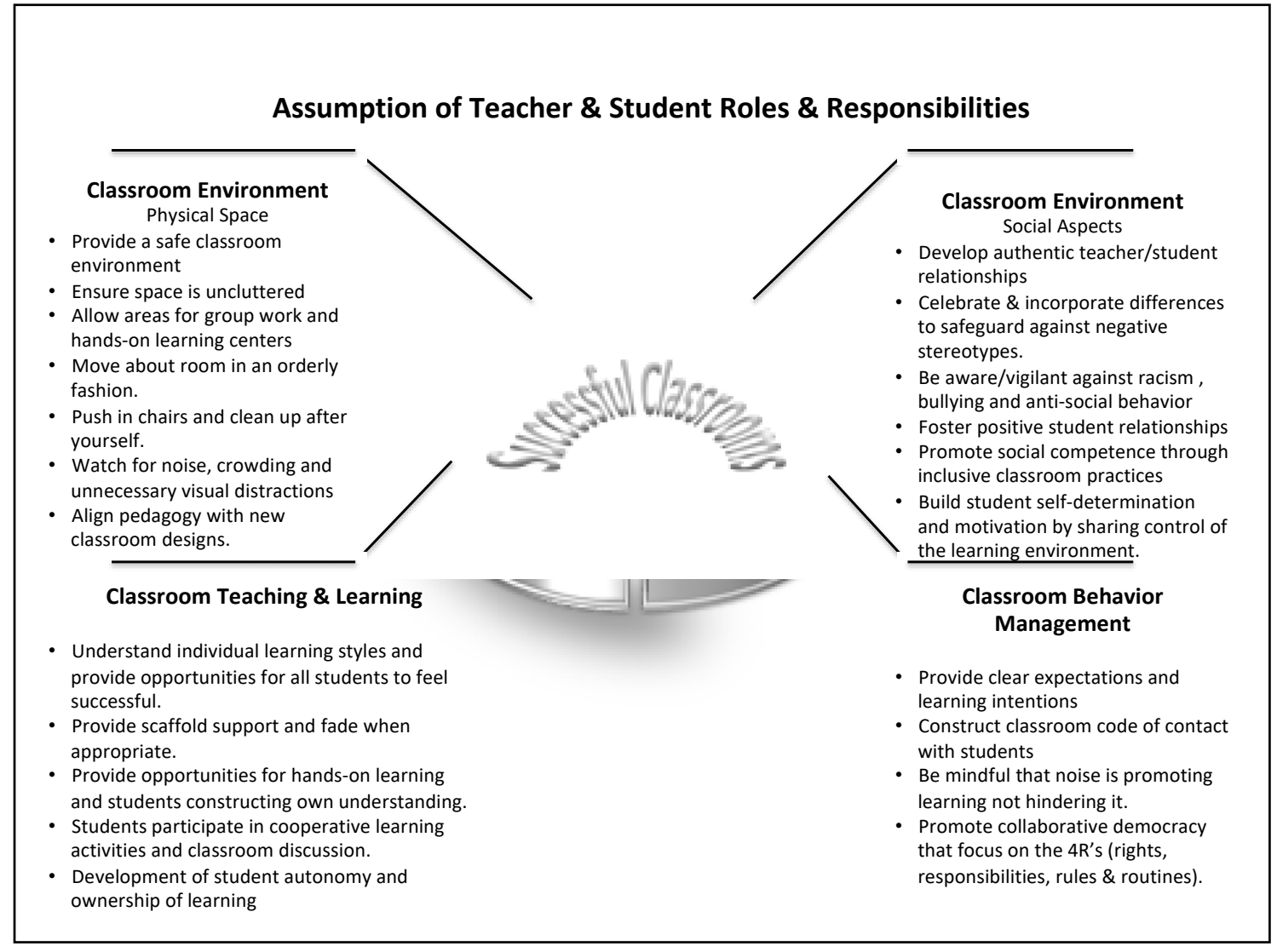

Figure 1. Assumption of Teacher and Student Roles and Responsibilities

A comprehensive review of the shared roles and responsibilities of the teacher and students that lead to effective classroom management and student engagement are defined in the following items.

\section{Teacher Roles}

Ladson-Billings (1995, p.160) proposed the phrase of "culturally relevant pedagogy" meaning that students must "i) experience success; ii) develop and/or maintain cultural competence; and iii) develop a critical consciousness through which they challenge the status quo of the current social order". In today's culturally diverse 21 st Century, the utilisation of culturally relevant pedagogy, and therefore multicultural education (Nieto \& Bode, 2009), is an essential part of a teacher's role. To achieve this multicultural ideal, teachers need to be aware of their own core beliefs and assumptions of themselves in their role as a teacher, and how they in turn view the role of students. A number of teacher roles are explored below, based on the perspective of how they can meet the complex needs students bring to today's classroom.

\subsection{Teacher as Career}

Teachers are required to create safe learning environments that are respectful and inclusive for the learning benefit of their students. Being kind, empathetic and understanding are only some of the character traits that create this safe learning space. While promoting learning, it also allows teachers the opportunity to connect with students individually.

Effective instruction requires teachers to have a solid understanding of their students, to know how they learn and to know what they are interested in. By acknowledging that all students approach learning differently with a variety of preferences for instruction (Vialle, Lysaght \& Verenikna, 2005), teachers are able to plan lessons to maximise engagement and promote autonomy and ownership of learning, where students choose excellence and mastery as their educational outcome (Ladson-Billings, 1995).

Arguably, the ability to learn independently is the primary aim of instructional education, regardless of the year level. However, independence is a learnt process that occurs through careful scaffolded support. Educators ensure students have adequate support to achieve the learning objectives, then gradually fade or remove the scaffolds as students begin to take more responsibility for their own learning (Larkin, 2001). To ensure scaffolds are effective, teachers are required to identify what their students already know, along with the gaps or misconceptions that are hindering further learning. By tailoring instruction to align with learning styles and extend a bridge from previously learnt to new learning, 
teachers help students achieve independence and promote further development (Larkin, 2001). Further, scaffolds are effective in transforming surface learning to higher-order thinking, by providing connections between ideas and activities (Lutz \& Huitt, 2004).

\subsection{Teacher as Role Model}

Aligned to Vygotsky's view that positive social interactions enhance cognitive development (Vialle et al., 2005), it is imperative for teachers to foster authentic, respectful relationships within the classroom. Teachers are responsible for modelling acceptable forms of communication, both verbally and non-verbally and to explicitly communicate expectations regarding mutual care and respect of others. Developing social competencies, friendships and peer acceptance promotes higher levels of classroom participation, motivation and resiliency (McCay \& Keyes, 2012).

To safeguard against harassment, bullying, racism, negative stereotypes and abuse, it is a teacher's responsibility to critically examine their own stereotypes and prejudicial attitudes, and to be aware of any underlying adverse attitudes existing within the classroom (Krause, Boucher, Duchesne \& McMaugh, 2010). Teachers and students alike need to work collaboratively and cooperatively in a shared environment that values differences and rewards interest in others.

Teachers' professionalism in thought, action and communication are not negotiable expectations and requirements in their role as educators. On a daily basis, teachers model ideal and appropriate responses to their peers, parents and students, as their reactions and inactions, responses and negotiations, are all witnessed and relay messages. Teacher actions reinforce and set the expectation of student behaviour: if teachers are disorganised, late to class, and ill-prepared, they cannot expect the opposite from their students if this is their modelled behaviour.

\subsection{Teacher as Creator}

The Australian Institute for Teaching and School Leadership (AITSL, 2014) provides a clear set of standards for teachers regarding the responsibilities they have toward their students and their own professional knowledge. If a teacher's role is to instruct, then paramount to this role is to instruct in a manner that reaches every student, improving educational outcomes and promoting personalised learning for all students, regardless of their background, level of advantage or disadvantage, or where they sit along the learning continuum (Ministerial Council on Education, Employment, Training and Youth Affairs (MCEETYA), 2008).

\subsubsection{Teacher and Student Needs}

The classroom social environment presents an interesting and dynamic interplay between what the teacher and the students perceive as positive, conducive to learning and mutually beneficial. In some ways, classrooms can be likened to an open economy of producers and consumers. Teachers aim to produce a product that will engage, motivate and attract focused and sustained attention, so in this sense, students are everyday consumers: if the environment or product on offer doesn't meet their needs or demands, then students will simply disengage. It is imperative to know therefore what our students want, and to identify where the similarities and differences lie in what teachers perceive to be ideal classroom environments. A review of these attributes (Ridley \& Walther, 1995) revealed that classroom discipline, rules and procedures were high on both the students' and teachers' requirements. Whilst these similarities present a positive direction for classroom management, there were two domains of student/teacher needs that highlight areas where conflicting and challenging priorities lie, particularly as students transition from primary to secondary school. These two domains encompass the broad ideologies of relationships and control.

\subsubsection{Building Relationships}

The first major obstacle in effective teaching and learning is a students' desire for genuine personal and affective relationships with their teacher. To meet this need teachers are required to invest in building strong and enduring relationships that display an interest and warmth for their students, extending beyond the classroom to their out of school identities (Ridley \& Walther, 1995). As students transition away from primary school with single classroom teachers into large high schools with a variety of subject specific educators, feelings of connectedness and belonging have been shown to diminish along with a decline in school motivation and engagement (Patrick \& Ryan, 2007; Schlosser, 1992).

Impacted by adolescents' general desire for autonomy and self-expression, relationship building presents a conflicting and challenging endeavour. The responsibility of establishing an atmosphere of mutual understanding and respect (Bondy, Ross, Gallingane \& Hambacher, 2007) is a two-way venture, relying on sustained and authentic effort from both teachers and students. Additionally, high impact teachers have been shown to humanise classroom learning through meaningful, related discussions in which personal stories are shared and students are encouraged to collectively solve problems and discuss real-world issues as a community of learners (Kohn, 1993; Schlosser, 1992). 


\subsubsection{Sharing Control of the Learning Environment}

Whilst useful in building a sense of belonging and connectivity, an egalitarian style of teaching helps to address and ameliorate the conflicting desire from both teachers and students to have a sense of control over the direction of learning (Ridley \& Walther, 1995). With an increasing reliance on standardised testing and teacher accountability, reluctance and willingness to share the control of the learning environment with students is understandable. However, controlling teaching strategies have a tendency to reduce students' self-determination, intrinsic motivation, feelings of competence and overall achievement (Grolnick \& Ryan, 1989; Ryan \& Deci, 2017). Further, allowing students to customise their learning facilitates personal responsibility and engagement (CAST, 2012). Just as teachers need to incorporate autonomy supportive lessons with clear structures and opportunities for students to take initiative in their learning, students need to respond positively by investing in deep-level learning through continued effort, perseverance and personal time management (Ryan \& Deci, 2017).

\subsection{Teacher as Student}

Despite the teacher's role to facilitate the learning of others, they too, continue to be life-long learners, improving their personal and professional practices for the sake of their current and future students' education. Students provide teachers with ongoing opportunities for self-reflection and self-improvement, opportunities to question how they approached a topic or activity and how effectively they interacted with their students. (Hosenfeld, 1976). Along with validating students as unique and complex learners, inquiring into the process of student learning shifts focus away from instruction and assessment and affords teachers insight into strategies students use to derive meaning.

\subsection{Teacher as Inspiration}

Despite an educator's responsibility to deliver the requirements of the National Curriculum, this should not translate as a limitation to how teaching manifests in the classroom. Teachers are constantly challenged to make learning relevant, meaningful and suitable. Incorporating creativity, imagination, fun and enjoyment transforms theory-based activities into fun, exciting and engaged learning (Johnson \& Johnson, 1999). This concept is confirmed by Nagro, Fraser and Hooks $(2018$, p.1) when describing the importance of teachers' "positive demeanour", explaining that to facilitate student achievement, teachers must display intensity and enthusiasm, therefore arousing student interest, and suggest the use of humour as a means of bolstering student engagement.

Aligned to Piaget's cognitive-developmental view of learning (Vialle et al., 2005), teachers need to provide meaningful hands-on learning tasks to allow room for students to make their own discoveries and construct their own knowledge, affording students an opportunity to become critical and relflective thinkers (Paul, 1990). Active learning is a pedagogical teaching method affording students opportunity to explore and engage with new material, whilst advancing their conceptual understanding (Clark, 2015). Although this approach has been demonstrated (Clark, 2015; Smith \& Cardaciotto, 2011) to be beneficial to all levels of learners regarding greater retention and engagement of material, research focusing on tertiary students' perception of active learning has indicated that older students consider hands-on learning experiences as superfluous and begrudge the additional effort (Smith \& Cardaciotto, 2011). Educators need to be considerate of the type of activities they incorporate into their lesson plans, ensuring they foster the integration of knowledge, promoting higher order thinking, rather than merely including behavioural activities (Smith \& Cardaciotto, 2011). Flipped classrooms have proved successful in secondary education, where educators utilise the digital environment to provide students with essential information prior to classroom activities (Clark, 2015). Students then have an opportunity to work through and explore their new knowledge with the assistance of the teacher and fellow classmates during classroom activities. This teaching method has been demonstrated to increase motivation, advance conceptual understanding and provide unique opportunities to engage in collaborative learning (Clark, 2015). Such techniques require students to be responsible for accessing the instructional information out of the classroom environment, prior to in-class activities.

\section{Student Roles}

Hattie's (2009) Visible Learning: A Synthesis of Over 800 Meta-Analyses Relating to Achievement, describes the major attributes students bring to school including: "background information such as prior achievement and personality dispositions, attitudes and dispositions, physical influences, and preschool experiences" (p. 40). The interpretation of Hattie's (2009) work regarding the role of students in the classroom is further explored.

\subsection{Student as Communicator}

Communication and learning are two-way active processes, with learning requiring both teachers and students to be effective communicators. Within a safe learning environment, students will be engaged, motivated and willing to discuss and share their ideas on learning through complex communicative exchanges based on the transmission of knowledge (Edwards \& Westgate, 1994). When teachers initiate discussion and allow room for students to use their voice, they are afforded valuable insight into how students think and what they already know. Rather than being passive 
recipients of instruction, when students take on the role of communicator, they use turn-taking strategies, verbal and nonverbal communication to reduce the social distance between themselves as pupils and the teacher and enhancing the understanding of knowledge, rather than simply acquiring it (Edwards \& Westgate, 1994).

\subsection{Student as Regulator}

Research has demonstrated self-regulation to be associated with high levels of academic achievement in the classroom (Schunk \& Zimmerman, 1997). A self-regulated learner is one that has the capacity to set personal goals, monitor their learning progress and moderate their behaviour to help them achieve their goals (Vialle et al., p.176, 2005). Allowing students choice in learning activities promotes goal setting, strategic planning and self-instruction (CAST, 2012). Explicitly teaching time management and planning skills by implementing checklists, encouraging students to write assessment designs, providing guidelines for time allocations and allowing opportunities for self-reflection are ways educators can facilitate student self-regulation.

\subsection{Student as Role Model}

Research has consistently supported how peer support and influence can positively influence and reinforce the power of the student as a role model to influence others' learning (Kagan, 1994; Lutz \& Huitt, 2004). Teachers facilitate constructivist-learning processors by placing students at the centre of their own learning, providing opportunities for personal discoveries, together with social, active and meaningful interactions between fellow classmates. Research by Kagan (1989; 1994) highlighted five principles: i) Positive interdependence; ii) Individual accountability; iii) Equal participation; iv) Group processing; and v) Simultaneous interaction. (PIEGS), that underpin cooperative learning that prepares students to be active, informed, flexible thinkers - capable of effective social interactions through enhanced cognitive development and emotional intelligence.

Positive interdependence ensures all students are responsible for the groups' successes or failures. Aligned to Vygotsky's theory of learners gaining knowledge through social processes (Lutz \& Huitt, 2004), teachers are responsible for organising learning tasks that allow students to extend their knowledge by socially interacting in a non-competitive, task orientated environment.

Individual accountability encourages students to contribute to the groups learning and be prepared to comment on both the contribution they made to the task and on the conclusions reached by the group. Teachers need to be aware of each student's abilities and strengths as the success of individual accountability rests with every student feeling they have something to offer. Jigsaw learning tasks provide students with valuable information they can contribute to their group.

Cooperative learning allows for the celebration of classroom diversity. Students are aware that they have something unique and valuable to add to their group and whilst equal participation does not necessarily mean equal amount, students are required to contribute their personal best. Having students share their ideas and ways of thinking helps to scaffold learning through discovery, processing, applying new knowledge and creating something they would not have been unable to achieve by working alone. Essentially, equal participation is a free exchange of ideas, with students encouraged to take risks in a supported environment (Johnson \& Johnson, 1999).

Group processing aids metacognitive development through the awareness of team Group processing aids metacognitive development through the awareness of team dynamics and social interactions. It provides students with time to understand how the group accommodated their contribution to the learning task and to ascertain how well their group achieved the learning outcomes. Fundamentally, time is the overriding factor leading to the success of group processing and with time being a limited commodity in classrooms, teachers are responsible for organising well-structured lessons that afford students necessary time to process their knowledge (Meador, 2019).

Simultaneous interaction ensures students are interacting in a meaningful way, extending their own knowledge and experiences through social interactions with peers, aimed at deepening understanding by creating a shared product that demonstrates the successful completion of the learning objectives. Advances in technology allow greater scope for the ways students can interact through digital learning environments inside and outside the classroom (Kong \& Song, 2013). Whilst students are responsible for their level of interaction and the manner in which they communicate, educators must amend their pedagogical practices to provide a variety of platforms and opportunities for students to participate in cooperative learning activities (Kong \& Song, 2013).

\subsection{Student as Challenger}

A lively and engaging classroom is conducive and most effective for stimulating curious and healthy learning. It is a sign of a safe environment that permits student engagement and encourages them to take control of their own education. Within this environment, teaching and learning are transformed into a two-way process where students can respectfully challenge the teacher, questioning possibilities requiring the teacher to re-think and reconsider both what they are teaching, and how they are teaching it. 
The ability to sustain effort and maintain persistence in challenging tasks is fundamental to the learning of new skills and strategies. Educators can help students build on maintaining focus and drive by establishing goals, setting short term objectives, providing scaffolds and rubrics and encouraging communication and collaboration with peers (Brand, Favazza \& Dalton, 2012; CAST, 2012). During whole-class and group discussions students should be encouraged to think out-loud, make predictions, question the process and discuss possible problems. Visible thinking affords students' insight into the thoughts of their peers, improves group cohesion, removes feelings of isolation and uncertainty and provides a platform to generate further thought.

\subsection{Student as Receptor}

Encompassed within a student's role is to be open to the idea of learning. Teachers should assume that all students are keen to learn and "want to please", which means that the responsibility lies with the teacher to keep students motivated to learn. Teachers can support the development of autonomy by offering opportunities for students to contribute to classroom decision-making processes, such as co-constructing rules and expectations, allowing students choice in how they will showcase their knowledge, utilising multiple means of assessment and providing rubrics where-by students can self-evaluate their own level of understanding (Stefanou, Perencevich, DiCinto \& Turner, 2004). Furthermore, working with students on developing individualised learning goals and learning intentions assists students in seeing where their knowledge is heading, aiding engagement, motivation and self-efficacy (Conley \& French, 2014). When students practice ownership of learning they are responsible for monitoring their own progress, seeking help when required, persevering and persisting during challenging tasks, managing their time effectively and setting achievable goals (Conley \& French, 2014).

\section{Classroom Environment - Physical Space}

Physical elements of the classroom play an important role in either promoting or hindering learning, with elements such as crowding and noise representing the main factors contributing to chaotic learning environments (Maxwell, 2008). Coupled with small classrooms and large numbers of students, activities designed to facilitate the construction of knowledge through hands-on inquiry has the propensity for chaos, leading to disruptive behaviours and students straying off tasks (Evans, 2006). Group work is fundamental to learning, however careful planning of activities and space needs to be considered. Being conscious of how activities will be designed and where students will complete the tasks should be a consideration in lesson planning to avoid overcrowding.

\subsection{Noise}

Active participation will impact upon noise levels in the classroom, as will students transitioning between activities, outside disruptions, multimedia and teacher presentations. Rather than shying away from group learning and hands-on inquiry, teachers need to ensure generated noise is constructive and not interfering with learning. Apart from hindering on-task behaviour, unproductive noise can interfere with attention, memory, speech perception and auditory discrimination (Maxwell, 2010). Explicitly pre-teaching requirements and expectations, providing quite zones for reflection and utilising redirection prompts (rhythm clapping) are some of the methods educators can employ to control noise. Students need to work respectfully, transition between tasks with minimal fuss and pay attention to teacher expectations.

\subsection{Crowding}

A combination of a large variety of activities involved in the lesson, the number of students and the size of the classroom all contribute to a propensity for chaos (Maxwell, 2006), which has been shown to lead to a drop-in concentration, disruptive behaviours and students straying off task (Evans, 2006). As such, classroom design and lesson timetabling require careful consideration. Strategies such as recruiting students to organise the classroom prior to their lunch break, utilising outdoor learning environments, dedicating specific areas for whole class discussion, demonstrations, group work and quiet zones would be useful in ameliorating chaos.

\subsection{Visual Complexity}

Excessive visual sources, such as posters, displays and student work samples can impact on overstimulating the senses and contributing to classroom chaos (Maxwell, 2006; Roskos and Neuman (2011) suggest limiting the amount of wall decorations and focusing on providing meaningful, uncluttered visual displays that capture attention and facilitate the learning of key concepts. Yet, visual scaffolds displaying group rules and expectations are helpful silent communication cues as a reference point for teacher and students to abide by.

\subsection{Classroom Design}

The call for an 'education revolution' (Imms \& Byers, 2017) has resulted in massive spending on technology integration in our classrooms, with classroom design the new frontier. As universities and schools move away from the 
traditional classroom setting, educators are left negotiating not only how to incorporate technology into pedagogical content knowledge, but also how to arrange the physical space to maximise instruction and manage student behaviour (Donnelly \& Berry, 2019). Open-Space learning, with flexible furniture integrated into visual and digital technologies encompassing multi-centric learning spaces, offers opportunities to enhance student learning experiences, engagement and performance (Imms \& Byers, 2017). However, such designs challenge the traditional learning space that placed the teacher in-front and centre of the classroom and sent a clear message to students of where to focus their attention and who was in-charge (Donnelly \& Berry, 2019). Therefore, teachers need to be aware of the messages these new environments sent to their students and how they may impact on behaviour. Clear guidelines establishing rules and routines need to be addressed to ensure the new designs do not detrimentally impinge on learning. Further, educators need to re-skill to ensure they are able to maximise the teaching and learning opportunities in these new spaces (Imms $\&$ Byers, 2017). When learning extends outside the traditional physical classroom into the digital arena, students are responsible for working within the boundaries of acceptable and safe behaviour.

\section{Classroom Behaviour Management}

Although the vast majority of student misbehaviours are low-level, including talking out of turn and engaging in off-task behaviours, research attributes such disruptions as a major contributor of teacher stress and self-efficacy, negatively impacting the learning environment and diminishing student engagement (Clunies-Ross, Little \& Kienhuis, 2008). Therefore, effective behaviour management strategies are imperative for both teacher well-being and academic achievement. Creating a positive classroom climate requires a careful balance of rules, fun and exploration, where misbehaviours are largely prevented from taking place to ensure effective learning occurs (McInerney \& McInerney, 2002). Whilst discipline is an aspect of classroom management, strong teacher leadership and thorough planning aimed at preventing or reducing misbehaviours from occurring is preferable.

A Positive Learning Framework (PLF), that utilises a three-phase model of prevention through self-awareness and management, lesson design and corrective action plans (McDonald, 2013) is an effective teaching strategy to increase student engagement by minimising misbehaviours. Under the PLF teachers are responsible for creating a safe and supportive classroom environment, where careful attention has been paid to the physical and social aspects of learning well before the students even enter the room. Considerations such as seating layout, classroom displays, group allocations, coupled with a clear understanding of rules, routines, procedures and consequences all fall under the umbrella of prevention. Likewise, lesson designs that link effective pedagogy with student motivation and engagement, such as active and collaborative learning, incorporating motivational 'hooks' and providing multiple means of representation and expression, are all effective ways to curtail misconduct. Whilst preventative strategies are fundamental in minimising misbehaviours, teachers need to be adept at designing and applying appropriate corrective actions when required. Various low-level responses, such as proximity, non-verbal communication and eye-contact are effective in minimising disruption to the flow of the lesson, but also provide the teacher with room to escalate responses according to the severity of the misbehaviours if required (McDonald, 2013).

Although the PLF relies on teacher implementation, acceptable classroom behaviour policies should be jointly constructed with student input through a process of collaborative democracy, where the 4R's of rules and routines are expressed as rights and responsibilities (McInerney \& McInerney, 2002). Classroom behaviour policies that are derived from a shared set of values are more meaningful for students than an indiscriminate set of rules imposed from the teacher (McInerney \& McInerney, 2002). Furthermore, by expressing rules as a set of rights that students are responsible for protecting, not only empower students to feel part of classroom management, but also affords them an opportunity to experience the democratic process.

\section{Developing a Vision of Classroom Management}

Successful classrooms where relevant, deep learning occurs foster an atmosphere of engagement, excitement and a desire to participate. These environments don't just happen - they are carefully constructed to accommodate a variety of student personalities, learning styles, academic rigor and behaviour management strategies. With a multitude of theoretical frameworks available to guide this vision of classroom management, four core beliefs regarding classroom behaviour management and student learning have been identified. These include:

\section{i) Classroom rules and teacher expectations need to be jointly constructed and explicitly taught at the beginning of the year.}

In order to deliver an authentic value driven approach to education, promoting democratic principles, students need to collaboratively work with teachers in establishing rules and procedures pertaining to classroom management (Kohn, 1993). When children become actively involved in their own management they not only experience a heightened sense of control, ownership and self-determination (Kohn, 1993), they are, according to Linda Albert's model of cooperative discipline, more likely to comply with behavioural expectations (Charles, 2005). Rather than simply telling students 
what they need to do, explicit instruction regarding 'how' and 'why' is an effective strategy in implementing procedures and routines belonging to well-managed, smooth running classroom. (Wong, n.d.). Further, classrooms that consistently demonstrate high levels of on-task behaviours and academic achievement have a tendency to establish and implement rules, procedures and routines at the beginning of the school year (Evertson \& Harris, 1992).

ii) Effective classroom planning and management is conducive to high levels of student learning and engagement, minimising unproductive behaviours.

Well-managed classrooms, with established procedures and routines use their time efficiently, maintaining momentum by spending less time on discipline and more time establishing learning (Lopes \& Oliveira, 2017; Wong, n.d). Students who feel that their time is being wasted are more likely to misbehave (McDonald, 2013), therefore implementing simple procedures for transitioning between lessons, students seeking help or teachers dealing with unnecessary interruptions, reduces disruptive, chaotic and unproductive behaviours (Freiberg, Templeton \& Helton, 2013). Additionally, lessons that run smoothly, free of misbehaviours and interruptions, generally result from well structured, detailed, student centred lesson plans (Evertson \& Harris, 1992; Wong, n.d).

iii) Misbehaviours will occur less when students are engaged in learning activities that are meaningful, relatable, well-paced, student-centred and achievable.

Providing opportunities for students to make decisions about what they are learning is a powerful tool in transforming apathy for student engagement (Kohn, 1993). The broad nature of the curriculum lends itself to teachers meeting the requirements of the syllabus whilst taping into the interests and real-world issues of their students. Motivation increases, and student misbehaviours decrease as students begin to see the learning activities as purposeful, and intrinsically valuable (Kohn, 1993). Good teachers however, understand that student motivation and participation is effected by a number of elements. Lopes and Oliveria (2017) draw attention to evidence of a link between academic rigour and misbehaviours, where students who fear an inability to complete the learning tasks have a tendency to disengage and practice off-task behaviours. Therefore, teachers must be adept at designing learning activities to accommodate student differences in ability and attention span, whilst building confidence through encouragement, without sacrificing high-level cognitive development in order to maintain classroom stability (Charles, 2005; Evertson \& Harris, 1992; Lopes \& Oliveria, 2017).

iv) The social and physical aspects of the classroom environment influence student behaviour and either support or hinder learning.

Linda Albert's model of cooperative discipline (Charles, 2005) is premised on the understanding that children need to feel like they belong in the classroom, are valued and are important contributors. Developing positive relationships through the five A's of acceptance, attention, appreciation, affirmation and affection often ameliorates misbehaviours by avoiding students mistaken goals of attention seeking, power seeking, revenge seeking and the avoidance of failure (Charles, 2005). Additionally, building a sense of belonging and community can also be achieved by holding classroom meetings, allowing students a voice through principles of self-determination, where students make decisions about their learning, leading to feelings of acceptance and respect (Kohn, 1993).

The Classroom Organisation and Management Program (COMP) developed by Evertson and Harris (COMP, 2012) builds on the importance of creating an inviting, well-structured classroom (Wong, n.d) by including the need for teachers to be aware of potential distractions that could lead to students working off-task and misbehaving. An over abundance of classroom decoration, traffic problems encountered during lesson transitions, and the arrangement of desks and zones of learning, represent some areas of the physical classroom environment that can hinder or support learning (COMP, 2012).

\section{Proactive and Reactive Classroom Management Strategies}

Prior to a landmark study by Kounin (1970), student misbehaviours and classroom disobedience was largely considered a problem within the student, with the authoritarian approach of forced compliance regarded as an effective strategy (Jessup, 1995). Since then, student transgressions are now generally regarded as arising from a classroom management perspective, leading to research and contemporary thinking focused on preventative measures (Jessup, 1995). Effective classroom management practices and pedagogical teacher skills are fundamental in ensuring disruptive behaviours do not adversely effect classroom learning. Acknowledging student misbehaviours will arise even in ideally managed classrooms, asserts the need for teachers to possess skills in minimising disruptions. Therefore, the skills teachers need to deal with misbehaviours have been divided into proactive and reactive domains aligned to McDonalds (2013) PLF. 


\subsection{Proactive Management Skills}

\subsubsection{Lesson Design}

Effective teachers utilise the skill of good lesson design to ensure classroom activities incorporate meaningful, authentic learning experiences with just the right amount of academic rigour and scaffolds to sit within the zone of proximal development for every student.

Disruptive misbehaviours that occur during lesson activities generally arise from students finding the work too challenging (Lopes \& Oliveira, 2017). However, even the most capable students need to see a purpose for the learning activity, with research (Lopes \& Oliveria, 2017) suggesting that if students perceive the activity to be unimportant or 'busy' work, they have a tendency to stray off task and cause disruptions. Furthermore, integrating purposeful movement that supports the curriculum has been demonstrated to alleviate disruptive behaviours, including inattention and hyperactivity, by increasing students' endurance for focus and learning (Nagro, Fraser \& Hooks, 2019).

\subsubsection{Implementing Effective Procedures and Routines}

Often disruptions to learning result from a lack of adequate procedures or routines, with smooth running classrooms linked to the teacher's skill in implementing and teaching the procedures (Wong, n.d.). When students understand procedures, such as what to do when they come into the classroom, how to get the teachers attention and how to transition between learning activities, they are less likely to disrupt the flow of the lesson, thus affect learning (Charles, 2005; Evertson \& Harris, 1992). Furthermore, ill defined rules and expectations have been demonstrated to result in increased problematic behaviours, poor classroom management, heightened teacher stress and diminished academic success (Clunies_Ross et al., 2008; Nagro et al., 2019).

\subsubsection{Pacing}

Effective teachers understand the nuances of timeframes and have the skill in knowing when they have spent enough time on both explanation and the learning activity. If the lesson appears to drag on, students become bored and begin to engage in off-task activities (McDonald, 2013). Likewise, if the amount of time on explicit explanations is insufficient, students may perceive the activity too challenging, stray off task, causing disruption to their learning and the learning of others (Lopes \& Oliveira, 2017).

\subsubsection{Antecedents}

Understanding the conditions or events t typically resulting in misbehaviours is fundamentally important in preventing them from occurring (Zirpoli, 2005). Taking time to examine the circumstances immediately prior to the inappropriate behaviour allows teachers and students to modify the antecedents, thereby decreasing the likelihood for the disruption in future instances. Additionally, students that frequently disrupt or display inappropriate higher-level misbehaviours, such as aggression, have benefitted from self-monitoring techniques that review antecedence as a means of behaviour management (Webber, Scheuermann, McCall \& Coleman, 1993).

\subsubsection{Proactive Praise}

Utilising praise as a means of preventing misconduct is an effective strategy in enhancing the classroom environment and decreasing disruptive, off-task behaviours. Frequent use of proactive praise has been shown to reduce low-level misbehaviours and promote higher levels of on-task performances, engagement and academic achievement (Clunies-Ross et al., 2008). However, studies have indicated that teachers have a tendency to direct positive proactive praise more likely toward academic work and rely on reactive negative responses for inappropriate behaviour issues, even though reactive strategies are less effective in managing behaviour (Clunies-Ross et al., 2008).

\subsection{Reactive Skills}

\subsubsection{Effective Use of Corrective Actions}

Arguably the most important skill teachers need to ensure disruptive behaviours do not adversely affect learning is the skill in knowing when and how best to implement corrective actions. A teacher's ability to closely monitor and deal with disruptive behaviours quickly, with minimal fuss, is imperative in maintaining classroom order (Evertson \& Harris, 1992). Whilst the majority of disruptions are considered low-level, teachers require skills to de-escalate potential higher level intensity misbehaviours and avoid power struggles (McDonald, 2013).

\subsubsection{Consistency}

After implementing classroom procedures and routines, it is fundamentally important that teachers respond to misconduct consistently (Wong, n.d.). Consistency is a skill that can be difficult to master especially when reacting to disruptions from students that constantly disrupt and those that rarely disrupt. However, responding in a consistent, predictable manner builds trust and ameliorates disruptive and chaotic learning environments (Freiberg, Templeton \& 
Helton, 2013). Furthermore, consistently responding to misbehaviours in a predicable manner, teaches students the relationship between misconduct and consequences (Zirpoli, 2005).

\subsubsection{Consequences}

Although low-level misbehaviours, such as talking out of turn, are generally regarded as annoying at worst, they are insidious and left untreated may transform into disruptive higher-level misconduct. Applying consequences for inappropriate behaviour should be short, to the point and immediate (Zirpoli, 2005). As described in the PLF, consequences range from simple non-verbal cues, like eye contact or pointing, to higher-level responses such as removal from the classroom (McDonald, 2013). When applying consequences, teachers should keep talk positive, redirecting the message of student rights and responsibilities (McInerney \& McInerney, 2002), and avoid reinforcing inappropriate behaviours by paying too much attention to the negative behaviour (Zirpoli, 2005).

\section{Conclusion}

Classrooms will continue to be shared learning spaces where nurturing the lives and building the knowledges of students will help shape their futures. Ensuring a positive schooling experience for teacher and student will rely on the flexibility, understanding, creativity and patience of both, to a culturally diverse demography of student and environmental factors. Collaboratively creating a learning environment that is both stimulating and inclusive demonstrating respect, empathy and trust is vital for learning, whilst the responsibility for the success of one's teaching and learning in the classroom remains squarely with the student and teacher.

\section{References}

Australian Institute for Teaching and School Leadership. (2014). Australian Professional Standards for Teachers. Retrieved from: https://www.aitsl.edu.au/teach/standards.

Bondy, E., Ross, D. D., Gallingane, C., \& Hambacher, E. (2007). Creating environments of success and resilience: Culturally responsive classroom management and more. Urban Education, 39, 266-289. Retrieved from: http://journals-sagepib-com.www,proxy1.library.unsw.edu.au/doi/abs/10.1177/0042085907303426

Brand, S. T., Favazza, A. E., \& Dalton, E. M. (2012). Universal Design for Learning: A Blueprint for Success for All Learners, Kappa Delta pi record, 48(3), 134-139. https://doi.org/10.1080/00228958.2012.707506

CAST. National Centre for Universal Design for Learning. (2012). Wakefield, MA. retrieved from: http://www.udlcentre.org/aboutudlguidelines.

Charles, C. M. (2005). Building classroom discipline ( $8^{\text {th }}$ ed.). Boston: Pearson/Allyn \& Bacon. Retrieved from: http://faculty.washington.edu/cadavis1/503\%20readings/AlbertChapter.pdf

Clark, K. R. (2015). The effects of the Flipped Model of Instruction on Student Engagement and Performance in the Secondary Mathematics Classroom. Journal of Educators Online, 12(1), 91-115. https://doi.org/10.9743/JEO.2015.1.5

Classroom Organisation and Management Program. (2012). Teacher tips. Retrieved from: http://www.comp.org/TOT.html

Clunies, R. P., Little, E., \& Kienhuis, M. (2008). Self-reported and actual use of proactive and reactive classroom management strategies and their relationship with teacher stress and student behaviour. Educational Psychology, 28(6), 693-710. https://doi.org/10.1080/01443410802206700

Conley, D. T., \& French, E. M. (2014). Student ownership of learning as a key component of college readiness. American behavioural Scientist, 58(8), 1018-1034. https://doi.org/10.1177/0002764213515232

Donnelly, J., \& Berry, L. (2019). Considering the environment: An expanded framework for teacher knowledge. Journal of Learning Spaces, 8(1), 42-48. Retrieved from: http://lbjournal.uncq.edu/jls/article/view/1834/1343

Edwards, A., \& Westgate, D. P. (1994). Investigating Classroom Talk. Revised and extended, $2^{\text {nd }}$ ed., Falmer Press, London; Washington D.C.

Evans, G. W. (2006). Child development and the physical environment. Annual Rev. Psychol., 57, 423-451. https://doi.org/10.1146/annurev.psych.57.102904.190057

Evertson, C. M., \& Harris, A. H. (1992). What we know about managing classrooms. Educational Leadership, 49(7), 74-78. Retrieved from: http://eric.ed.gov/?id=EJ442798

Freiberg, J. H., Templeton, S. M., \& Helton, S. (2013). Classroom management: A pathway to improving school climate in two British secondary schools. In M. Newberry, A. Gallant, Riley \& S. Pinnegar (Eds.), Emotion and School: How the hidden curriculum influences relationships, leadership, teaching and learning. (pp. 203-225). Bingley, 
United Kingdom: Emerald Group Publishing Limited. https://doi.org/10.1108/S1479-3687(2013)0000018015

Grolnick, W. S., \& Ryan, R. M. (1989). Parent styles associated with children's self-regulation and competence in school. Journal of Educational Psychology, 81(2), 143-154. https://doi.org/10.1037/0022-0663.81.2.143

Hattie, J. (2009). Visible learning: A synthesis of over 800 meta-analyses relating to achievement. Routledge, London, New York. https://doi.org/10.4324/9780203887332

Hattie, J. (2013). Why are so many of our teachers and schools so successful? John Hattie at TEDxNorrkoping. Retrieved from: https://www.youtube.com/watch? $\mathrm{v}=\mathrm{rZwJXUieD0U}$

Hosenfeld, C. (1976). Learning about learning: Discovering our students' strategies. Foreign Language Annals, 9(2), 117-129. https://doi.org/10.1111/j.1944-9720.1976.tb02637.x

Imms, W., \& Byers, L. (2017). impact of classroom design on teacher pedagogy and student engagement and performance in mathematics. Learning Research, 20(1), 139-152. https://doi.org/10.1007/s10984-016-9210-0

Jessup, S. (1995). Teacher perceptions of the essential skills in classroom management and discipline. University of Wollongong thesis collection. Retrieved from: http://ro.uow.edu.au/theses/2350

Johnson, D. W., \& Johnson, R. (1999). Making cooperative learning work. Theory Into Practice, 38(2), 67-73. https://doi.org/10.1080/00405849909543834

Kagan, S. (1989). The structural approach to cooperative learning. Educational Leadership, Dec 89/ Jan 90, 12-15.

Kagan, S. (1994). Cooperative Learning, Resources for Teachers. San Juan Capistrano, CA: Kagan Cooperative Learning.

Kohn, A. (1993). Choices for children: Why and how to let students decide. Phi Delta Kappan, 75(1), 8-20. Retrieved from: http://search.proquest.com.ezproxy.une.au

Kong, S. C., \& Song, Y. (2013). A principle-based design framework for developing constructivist learning in a seamless learning environment: A teacher development model for learning and teaching in digital classrooms. British Journal of Educational Technology, 44(6), E209-E212. https://doi.org/10.1111/bjet.12073

Kounin, J. S. (1970). Discipline and group management in classrooms. New York: Holt, Rinehart and Winston.

Krause, L., Bocher, S., Duchesne, S., \& McMaugh, A. (2010). Educational Psychology for Learning and Teaching. South Melbourne: Cengage.

Ladson-Billings, G. (1995). But that's just good teaching!: The case for culturally relevant pedagogy. Theory Into Practice, 34(3), 159-165. https://doi.org/10.1080/00405849509543675

Larkin, M. J. (2001). Providing Support for Student Independence through Scaffolded Instruction. Teaching Exceptional Children, 34(1), 30-34. https://doi.org/10.1177/004005990103400104

Lopes, J., \& Oliveira, C. (2017). Classroom discipline: Theory and practice. In J. P. Bakken (Ed), Classrooms: Academic content and behaviour strategy instruction for students with and without disabilities. 2, 231-253. Retrieved from: http://www.research.net/publication/319178957_Classroom_Discipline_Theory_and_Practice

Lutz, S., \& Huitt, W. (2004). Connecting cognitive development and constructivism: Implications from theory for instruction and assessment. Constructivism in the Human Sciences, 9(1), 67-90. Retrieved from: http://www.scribd.com/document/204267247/Cognitive-Development

Maxwell, L. (2010). Chaos outside the home: The school environment. In Evans, G., \& Theodore, W. (Eds), Chaos and its influence on children's development: An ecological perspective. American Psychological Association, Washington DC, (2010), 83-95. https://doi.org/10.1037/12057-006

McCay, L. \& Keyes, D. (2012). Developing social competence in the inclusive primary classroom. Childhood Education, 78 (2), 70-78. https://doi.org/10.1080/00094056.2002.10522707

McDonald, T. (2013). Classroom Management: Engaging Students in Learning. South Melbourne: Oxford University Press.

McInerney, D., \& McInerney, V. (2002). Educational Psychology: Constructing Learning. Frenchs Forest, NSW: Pearson Education Australia.

Meador, D. (2019, June 24). Strategies for Teachers to Maximize Student Learning Time. Retrieved from: $\mathrm{http}: / / \mathrm{www}$.thoughtco.com/strategies-for-teachers-to-maximize-student-learning-time-4065667

Ministerial Council on Education, Employment, Training and Youth Affairs (MCEETYA). (2008). Melbourne Declaration on Educational Goals for Young Australians. Retrieved from: 
http://www.curriculum.edu.au/verve/_resources/National_Declaration_on_the_Educational_Goals_for_Young_Aus tralians.pdf

Nagro, S. A., Fraser, D. W., \& Hooks, S.D. (2018). Lesson Planning With Engagement in Mind: proactive Classroom Management Strategies for Curriculum Instruction. Intervention in School and Clinic, 54(3), 131-140. https://doi.org/10.1177/1053451218767905

Nieto, S. \& Bode, P. (2009). 'Multicultural education and school reform', Affirming diversity: The socio-political context of multicultural education, 5th ed, Pearson, Sydney, pp. 42-62.

Organisation for Economic Co-operation and Development (OECD). (2005). Teachers matter: Attracting, developing and retaining effective teachers. retrieved from: http://www.oecd.org/education/school/34990905.pdf

Patrick, H., \& Ryan, A. M. (2007). Early adolescents' perceptions of the classroom social environment, motivational beliefs and engagement. Journal of Educational Psychology, 99(1), 88-98. https://doi.org/10.1037/0022-0663.99.1.83

Paul, R. (1990). Critical thinking: What, Why and How: In Paul, R., \& Binker, J. (Eds), Critical thinking: What Every Person Needs to Survive in a Rapidly Changing World. pp. 45-56. Rohnet Park, CA: Centre for critical thinking and moral critique, Sonoma State University.

Ridley, D. S., \& Walther, B. (1995). Creating responsible learners: The role of a positive classroom environment. Washington, D.C.: American Psychological Association. https://doi.org/10.1037/10181-000

Ryan, R. M., \& Deci, E. L. (2017). Self-Determination theory: Basic Psychological needs in motivation, development \& wellness, 352-381. New York: Guilford Publications.

Schlosser, L. K. (1992). Teacher Distance and Student Disengagement: School Lives on the Margin. Journal of Teacher Education, 43(2), 128-140. https://doi.org/10.1177/0022487192043002006

Schunk, D. H., \& Zimmermanm, B. J. (1997). Social origins of self-regulatory competence, Educational Psychologist, 32(4), 195-208. https://doi.org/10.1207/s15326985ep3204_1

Smith, C. V., \& Cardaciotto, L. (2011). Is active learning like broccoli? Student perceptions of active learning in large lecture classes. Journal of the Scholarship of Teaching and Learning, 11(1), 53-61.

Stefanou, C. R., Perencevich, K. C., DiCintio, M., \& Turner, J. C. (2004). Supporting Autonomy in the Classroom: Ways Teachers Encourage Student Decision Making and Ownership, Educational Psychology, 39(2), 97-110. https://doi.org/10.1207/s15326985ep3902_2

Vialle, W., Lysaght, P., \& Verenikina, I. (2005). Psychology for educators. South Melbourne, Victoria, Cengage Learning.

Webber, J., Scheuemann, B., McCall, C., \& Coleman, M. (1993). Research on Self-Monitoring as a Behaviour management Technique in Special Education Classrooms: A Descriptive Review. Remedial and Special Education, 14(2), 38-56. https://doi.org/10.1177/074193259301400206

Wong, H. (n.d.). The well-managed classroom. Retrieved from: http://wtc.ie/images/pdf/Classroom_Management/cm6.PDF

Zirpoli, T. J. (2005). Behaviour Management: Application for Teachers. New Jersey, Columbus, Ohio: Pearson Merrill Prentice Hall.

\section{Copyrights}

Copyright for this article is retained by the author(s), with first publication rights granted to the journal.

This is an open-access article distributed under the terms and conditions of the Creative Commons Attribution license which permits unrestricted use, distribution, and reproduction in any medium, provided the original work is properly cited. 